\title{
Effects of Bamboo Salt with Sodium Fluoride on the Prevention of Dental Caries
}

\author{
Hye-Jin Lee ${ }^{1, \dagger}$, A-Reum Park ${ }^{2}$, and Han-Na Oh ${ }^{2}$ \\ 'Department of Dental Hygiene, Howon University, Gunsan 54058, \\ ${ }^{2}$ Department of Dental Hygiene, Wonkwang Health Science University, Iksan 54538, Korea
}

\begin{abstract}
Background: Dental caries is one of several prevalent oral diseases caused by dental plaque biofilms. This study evaluated the anti-cariogenic effects of a bamboo salt (BS) and sodium fluoride ( $\mathrm{NaF}$ ) mixture on oral bacteria.

Methods: The effects of several mixtures of $\mathrm{NaF}$ and $\mathrm{BS}$ on acid production, growth, and adhesion to glass beads of Streptococcus mutans, and their anti-cariogenic properties were investigated. The growth of $S$. mutans was measured according to optical density at $3,6,9,12,15,18$, and 24 hours after treatment using spectrophotometry at a wavelength of $600 \mathrm{~nm}$, while pH was measured using a pH meter. Adhesion of $S$. mutans was measured according to the weight of glass beads from each group before and after incubation. Gene expression was measured using real-time polymerase chain reaction. Acid production and growth patterns of $S$. mutans were compared using repeated measures analysis of variance, followed by Scheffe's post-hoc test. The Kruskal-Wallis test was used to compare adhesion, followed by the Mann-Whitney test. Gene expression in the experimental and control samples was compared using the Student's t-test.

Results: Growth, acid production, and adhesion of $S$. mutans were inhibited in all experimental groups. Expression of $g f t$ and fructosyltransferase in $S$. mutans was inhibited in all groups. A mixture of $\mathrm{NaF}$ and $\mathrm{BS}$ significantly reduced growth, acid production, adhesion, and gene expression of $S$. mutans compared with the other groups.

Conclusion: Results of the present study demonstrated that a mixture of $\mathrm{NaF}$ and BS was useful as a mouth rinse in preventing dental caries.
\end{abstract}

Key Words: Bamboo salt, Dental caries, Sodium fluoride, Streptococcus mutans

\section{Introduction}

Dental caries is defined by dissolution of the tooth surface by acid produced from cariogenic microorganisms, especially Streptococcus mutans ${ }^{1)}$. One significant characteristic of $S$. mutans in caries development is its ability to adhere to the tooth surface. S. mutans produces extracellular glucosyltransferase $(g t f \mathrm{~B}, g t f \mathrm{C}, g t f \mathrm{D}$, and fructosyltransferase $(f t)$ in the presence of sucrose, which are important in the formation of plaque and in the processes leading to dental caries ${ }^{2}$. To prevent dental caries and periodontal disease, it is essential to inhibit the formation of dental plaque on tooth surfaces. In this context, anti- microbial agents could serve as a valuable complement to mechanical plaque removal.

Bamboo salt (BS) is a Korean traditional salt. It is prepared by packing bay salt in bamboo, then baking it nine times in high heat using pine firewood. Through this process, the impurities in the bay salts are removed while its inorganic contents, including calcium, potassium, copper and zinc ions, and alkalinity, are increased compared to sun-dried salts (SDS) ${ }^{3)}$. BS is known to have therapeutic effects for ailments including viral and bacterial infections, and inflammatory disorders ${ }^{4)}$. The remineralization effects of BS on incipient artificial enamel caries have also been described ${ }^{5)}$. Thus, BS can be considered a 
useful anti-microbial agent for the inhibition of dental plaque.

Sodium fluoride $(\mathrm{NaF})$ is considered to play an important role in the prevention of dental caries, primarily due to its remineralization effect on decalcified tooth surfaces. Another advantage of fluoride is its ability to decrease acid formation in dental plaque, especially by $S$. mutans. Several studies investigating the effect of mouth rinses of diverse chemical composition(s) demonstrated that compound substances of $\mathrm{NaF}$ and other chemical agents are able to inhibit the metabolic activity of microorganisms in the dental biofilm ${ }^{6-8)}$. The combination of BS and $\mathrm{NaF}$ is used as a component of dentifrice for the prevention of dental caries in Korea. A previous report described the remineralization effect of the combination of $\mathrm{BS}$ and $\mathrm{NaF}^{5}$; however, no study has determined its anti-microbial activity and mechanism of action in the inhibition of $S$. mutans, which is a pathogenic oral microorganism. As such, studies are needed to evaluate the antimicrobial activity and the mechanism of the anti-microbial effect of the combination of BS and $\mathrm{NaF}$ on S. mutans.

The objective of the present study, therefore, was to investigate the anti-microbial effect of $\mathrm{NaF}$ and $\mathrm{BS}$, and whether $\mathrm{NaF}$ and BS can modify the cariogenic properties of $S$. mutans, including growth, acid production, and adhesion.

\section{Materials and Methods}

\section{Preparation of solution}

BS was provided by Insanga Food Inc. (Insanga Bamboo salt 9; Insanga, Hamyang, South Korea). BS (3\% and $5 \%$ ) was used in this study, and has previously been shown to inhibit the growth of $S$. mutans effectively ${ }^{9}$. $\mathrm{NaF}$ was purchased from Sigma-Aldrich (St. Louis, MO, USA). $\mathrm{NaF}(0.02 \%$ and $0.05 \%)$ was used in this study as a mouth rinse solution.

\section{Measurement of Streptococcus mutans growth and acid production}

S. mutans, American Type Culture Collection accession number 31,989 , was used in this study. S. mutans was inoculated in brain heart infusion (BHI; Difco, Detroit,
MI, USA) broth and incubated at $37^{\circ} \mathrm{C}$ for 24 hours. The optical density (OD; i.e., absorbance) of each culture was then measured at a wavelength of $600 \mathrm{~nm}$ to calculate the number of $S$. mutans to use in the experiments $\left(1.6 \times 10^{8}\right.$ colony forming units/ml).

BHI broth containing $10 \%$ glucose and different concentrations of $\mathrm{NaF}$ and $\mathrm{BS}$ mixture $(3 \% \mathrm{BS}, 0.02 \% \mathrm{NaF}$, $0.05 \% \mathrm{NaF}, 0.02 \% \mathrm{NaF}+3 \% \mathrm{BS}$, and $0.05 \% \mathrm{NaF}+3 \% \mathrm{BS}$ ) was prepared. The growth of $S$. mutans was measured at 3 , $6,9,12,15,18$, and 24 hours using spectrophotometry (EZ Read 400; Biochrom, Cambridge, UK) according to OD at a wavelength of $600 \mathrm{~nm}\left(\mathrm{OD}_{600}\right)$. $\mathrm{pH}$ was measured at 2, 4, $8,12,16,20$, and 24 hours using a pH meter (920A; Thermo Orion, Beverly, MA, USA).

\section{Analysis of adherence properties}

BHI agar broth containing $10 \%$ glucose and different concentrations of $\mathrm{NaF}$ and $\mathrm{BS}$ mixture (3\% BS, $0.02 \%$ $\mathrm{NaF}, 0.05 \% \mathrm{NaF}, 0.02 \% \mathrm{NaF}+3 \% \mathrm{BS}$, and $0.05 \% \mathrm{NaF}+$ $3 \% \mathrm{BS}$ ) was prepared. The weight of glass beads for each group was measured, and then $5 \mathrm{ml}$ of experimental solution was poured onto the beads in each group. The mixture was incubated at $37^{\circ} \mathrm{C}$ for 24 hours and the experimental solution was removed, followed by addition of $75 \%$ ethanol to the plate. After drying, the weight of the glass beads was measured ${ }^{10)}$. The experiment was performed in triplicate.

Table 1. Nucleotide Sequence of RT-PCR Primers for Genes

\begin{tabular}{lll}
\hline $\begin{array}{c}\text { Gene } \\
\text { description }\end{array}$ & Direction & \multicolumn{1}{c}{ Nucleotide sequence (5'-3') } \\
\hline$g t f$ B & Forward & AGCAATGCAGCCATCTACAAAT \\
& Reverse & ACGAACTTTGCCGTTATTGTCA \\
$g t f C$ & Forward & GGTTTAACGTCAAAATTAGCTGTATTAGC \\
& Reverse & GGTTAACGTCAAAATTAGCTGTATTAGC \\
$g t f \mathrm{D}$ & Forward & CACAGGCAAAAGCTGAATTAACA \\
& Reverse & GAATGGCCGCTAAGTCAACAG \\
$f t f$ & Forward & AATCCCTATCAACCTCGACTGC \\
& Reverse & GCCTTTCTCCTGCAACCAAATC \\
$16 s$ rRNA & Forward & CCTACGGGAGGCAGCAGTAG \\
& Reverse & CAACAGAGCTTTACGATCCGAAA \\
\hline
\end{tabular}

RT-PCR: reverse transcription polymerase chain reaction, ftf: fructosyltransferase. 


\section{Measurement of bacterial gene expression} using real-time polymerase chain reaction

Total RNA was purified using a commercially available kit (RNeasy Mini Kit; Qiagen, Venlo, The Netherlands). The primer sequences are provided in Table 1. Polymerase chain reaction conditions included an initial denaturation at $95^{\circ} \mathrm{C}$ for 15 minutes, followed by 40 -cycle amplification consisting of denaturation at $94^{\circ} \mathrm{C}$ for 15 seconds and primer annealing at $55^{\circ} \mathrm{C}$ for 30 seconds, and extension at $72^{\circ} \mathrm{C}$ for 30 seconds. The expression levels of $g t f \mathrm{~B}, g t f \mathrm{C}$, $g t f \mathrm{D}$, and $\mathrm{ftf}$ were normalized using the $16 \mathrm{~S}$ ribosomal RNA gene as an internal standard.

\section{Statistical analysis}

Data analysis was performed using SPSS ver. 18.0 (IBM Corp., Armonk, NY, USA). Repeated measures ANOVA was used for acid production and growth patterns of $S$. mutans, followed by Scheffe's post-hoc test. Adhesion was analyzed using the Kruskal-Wallis test, followed by the Mann-Whitney test. Differences in gene expression in the experimental and control samples were analyzed using the Student's t-test.

Table 2. Change of $\mathrm{pH}$ in Culture Medium after the Incubation

\begin{tabular}{ccccccc}
\hline \multirow{2}{*}{ Time $(\mathrm{h})$} & \multicolumn{5}{c}{ Group $^{*}$} \\
\cline { 2 - 7 } & Control $(\mathrm{BHI})^{\mathrm{a}}$ & $3 \% \mathrm{BS}^{\mathrm{d}}$ & $0.02 \% \mathrm{NaF}^{\mathrm{b}}$ & $0.05 \% \mathrm{NaF}^{\mathrm{c}}$ & $0.02 \% \mathrm{NaF}+3 \% \mathrm{BS}^{\mathrm{e}}$ & $0.05 \% \mathrm{NaF}^{\mathrm{a}} 3 \% \mathrm{BS}^{\mathrm{e}}$ \\
\hline 0 & $7.18 \pm 0.00$ & $7.35 \pm 0.00$ & $7.20 \pm 0.01$ & $7.18 \pm 0.00$ & $7.33 \pm 0.01$ & $7.35 \pm 0.00$ \\
2 & $7.18 \pm 0.00$ & $7.35 \pm 0.00$ & $7.16 \pm 0.00$ & $7.15 \pm 0.00$ & $7.31 \pm 0.01$ & $7.31 \pm 0.01$ \\
4 & $7.09 \pm 0.00$ & $7.26 \pm 0.00$ & $7.14 \pm 0.00$ & $7.15 \pm 0.00$ & $7.29 \pm 0.00$ & $7.28 \pm 0.00$ \\
8 & $7.01 \pm 0.00$ & $7.25 \pm 0.00$ & $7.08 \pm 0.00$ & $7.15 \pm 0.00$ & $7.24 \pm 0.00$ & $7.25 \pm 0.01$ \\
12 & $6.71 \pm 0.01$ & $7.24 \pm 0.00$ & $6.95 \pm 0.01$ & $7.15 \pm 0.00$ & $7.24 \pm 0.00$ & $7.24 \pm 0.01$ \\
16 & $5.30 \pm 0.00$ & $7.21 \pm 0.03$ & $6.82 \pm 0.00$ & $7.12 \pm 0.01$ & $7.25 \pm 0.01$ & $7.26 \pm 0.00$ \\
20 & $4.30 \pm 0.00$ & $7.08 \pm 0.00$ & $6.71 \pm 0.00$ & $7.08 \pm 0.01$ & $7.18 \pm 0.00$ & $7.22 \pm 0.02$ \\
24 & $4.18 \pm 0.01$ & $7.08 \pm 0.01$ & $6.58 \pm 0.01$ & $7.08 \pm 0.01$ & $7.18 \pm 0.00$ & $7.21 \pm 0.01$ \\
\hline
\end{tabular}

Values are presented as mean \pm standard deviation.

BHI: brain heart infusion, BS: bamboo salt, NaF: sodium fluoride.

${ }^{*} \mathrm{p}<0.01$, by repeated measures ANOVA.

${ }_{\text {a.b,c,d,e }}^{*}$ The same letter indicates no significant difference by Scheffe.

Table 3. Inhibitory Effects of $\mathrm{BS}$ and $\mathrm{NaF}$ on the Streptococcus mutans Growth

\begin{tabular}{ccccccc}
\hline \multirow{2}{*}{ Time (h) } & \multicolumn{5}{c}{ Group $^{*}$} \\
\cline { 2 - 6 } & Control $(\mathrm{BHI})^{\mathrm{a}}$ & $3 \% \mathrm{BS}^{\mathrm{b}}$ & $0.02 \% \mathrm{NaF}^{\mathrm{b}}$ & $0.05 \% \mathrm{NaF}^{\mathrm{c}}$ & $0.02 \% \mathrm{NaF}+3 \% \mathrm{BS}^{\mathrm{c}}$ & $0.05 \% \mathrm{NaF}^{\mathrm{a}}+3 \% \mathrm{BS}^{\mathrm{d}}$ \\
\hline 0 & $0.06 \pm 0.00$ & $0.06 \pm 0.00$ & $0.06 \pm 0.00$ & $0.06 \pm 0.00$ & $0.06 \pm 0.00$ & $0.06 \pm 0.00$ \\
3 & $0.06 \pm 0.00$ & $0.06 \pm 0.00$ & $0.06 \pm 0.00$ & $0.07 \pm 0.01$ & $0.06 \pm 0.00$ & $0.06 \pm 0.00$ \\
6 & $0.07 \pm 0.00$ & $0.07 \pm 0.00$ & $0.07 \pm 0.00$ & $0.07 \pm 0.00$ & $0.07 \pm 0.00$ & $0.06 \pm 0.00$ \\
9 & $0.20 \pm 0.00$ & $0.10 \pm 0.00$ & $0.15 \pm 0.00$ & $0.09 \pm 0.01$ & $0.09 \pm 0.00$ & $0.06 \pm 0.00$ \\
12 & $0.31 \pm 0.00$ & $0.22 \pm 0.01$ & $0.22 \pm 0.00$ & $0.11 \pm 0.00$ & $0.13 \pm 0.00$ & $0.07 \pm 0.00$ \\
15 & $0.29 \pm 0.01$ & $0.24 \pm 0.00$ & $0.22 \pm 0.00$ & $0.14 \pm 0.01$ & $0.16 \pm 0.00$ & $0.07 \pm 0.00$ \\
18 & $0.28 \pm 0.02$ & $0.24 \pm 0.01$ & $0.21 \pm 0.00$ & $0.14 \pm 0.01$ & $0.16 \pm 0.00$ & $0.07 \pm 0.00$ \\
21 & $0.28 \pm 0.00$ & $0.21 \pm 0.02$ & $0.20 \pm 0.00$ & $0.14 \pm 0.01$ & $0.15 \pm 0.00$ & $0.07 \pm 0.00$ \\
24 & $0.28 \pm 0.00$ & $0.22 \pm 0.00$ & $0.19 \pm 0.00$ & $0.14 \pm 0.00$ & $0.15 \pm 0.01$ & $0.07 \pm 0.00$ \\
\hline
\end{tabular}

Values are presented as mean \pm standard deviation.

BHI: brain heart infusion, $\mathrm{BS}$ : bamboo salt, $\mathrm{NaF}$ : sodium fluoride.

${ }^{*} \mathrm{p}<0.01$, by repeated measures ANOVA.

${ }_{\text {a.b,c,d }}$ The same letter indicates no significant difference by Scheffe. 


\section{Results}

\section{Effects of NaF and bamboo salt on the acidogenicity of Streptococcus mutans}

After 24 hours, the $\mathrm{pH}$ value of all experimental groups was $>6.5$ and exhibited significantly increased values compared with the control group. $\mathrm{pH}$ reduction was lower in the $0.02 \% \mathrm{NaF}+3 \% \mathrm{BS}$ and $0.05 \% \mathrm{NaF}+3 \% \mathrm{BS}$ groups compared with the other groups $(\mathrm{p}<0.01)$ (Table 2$)$.

\section{Inhibitory effects of NaF and bamboo salt on the growth of Streptococcus mutans}

After 24 hours, the growth of $S$. mutans was inhibited by $50 \%$ and $75 \%$ compared with that of the control group when treated with $0.02 \% \mathrm{NaF}+3 \% \mathrm{BS}$ and $0.05 \% \mathrm{NaF}+$ $3 \% \mathrm{BS}$, respectively. The inhibitory rates were $25 \%$ and $50 \%$, when treated with $0.02 \% \mathrm{NaF}$ and $0.05 \% \mathrm{NaF}$, respectively $(\mathrm{p}<0.01)$ (Table 3$)$.

\section{NaF and bamboo salt inhibited Streptococcus mutans adhesion to glass beads}

The effect of NaF and BS on the adhesion of S. mutans to glass beads was examined. The combination of $0.05 \%$ $\mathrm{NaF}+3 \%$ BS significantly inhibited the adhesion of $S$. mutans (Table 4).

\section{Expression of $g t f$ and $f t f$}

The expression of $g t f$ and $f t f$ was decreased in the $\mathrm{NaF}$ and BS group compared with the control group (Fig. 1). Messenger RNA expression of $g t f \mathrm{~B}, g t f \mathrm{C}, g t f \mathrm{D}$, and $f t f$ was decreased in the $\mathrm{NaF}$ and $\mathrm{BS}$ group compared with the control group.

\section{Discussion}

Dental caries is caused by bacteria in dental biofilms. Pathogenic bacteria can adhere to tooth surfaces using an extracellular polymer termed the "glycocalyx", leading to biofilm formation ${ }^{2)}$. Because $S$. mutans has been established as the primary causative factor of dental caries, inhibiting $S$. mutans adhesion to the tooth surface could be one major approach to the prevention of dental caries ${ }^{11)}$. In recent years, several anti-caries agents, such as $\mathrm{NaF}$, tea polyphenols, triclosan and chlorhexidine, have been widely studied for preventing dental caries through the inhibition of biofilm formation ${ }^{12-14)}$. In this study, we evaluated the

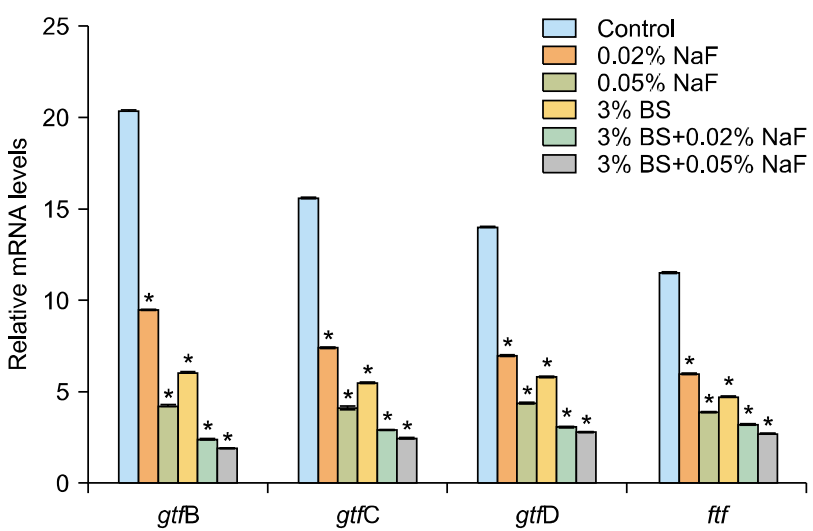

Fig. 1. Effects of bamboo salt (BS) and sodium fluoride (NaF) on $g t f$ and fructosyltransferase ( $f t f)$ expression in Streptococcus mutans. ${ }^{*} p<0.05$.

Table 4. The Adhesion of Streptococcus mutans to Glass Beads

\begin{tabular}{lccc}
\hline \multicolumn{1}{c}{ Group } & \multicolumn{2}{c}{ Weight of glass beads (mg) } & \multicolumn{2}{c}{ After } \\
\cline { 2 - 4 } & Before & $815.01 \pm 29.53$ & $1.08 \pm 0.09^{\mathrm{a}}$ \\
\hline Control $(\mathrm{BHI})$ & $813.92 \pm 29.54$ & $803.93 \pm 70.83$ & $0.66 \pm 0.14^{\mathrm{b}}$ \\
$0.02 \% \mathrm{NaF}$ & $803.27 \pm 70.86$ & $818.85 \pm 70.83$ & $0.46 \pm 0.19^{\mathrm{c}}$ \\
$0.05 \% \mathrm{NaF}$ & $818.38 \pm 79.48$ & $808.45 \pm 66.33$ & $0.56 \pm 0.19^{\mathrm{bc}}$ \\
$3 \% \mathrm{BS}$ & $807.88 \pm 66.29$ & $805.43 \pm 41.97$ & $0.35 \pm 0.17^{\mathrm{cd}}$ \\
$0.02 \% \mathrm{NaF}+3 \% \mathrm{BS}$ & $805.08 \pm 41.88$ & $774.95 \pm 56.56$ & $0.25 \pm 0.07^{\mathrm{d}}$ \\
$0.05 \% \mathrm{NaF}+3 \% \mathrm{BS}$ & $774.70 \pm 56.59$ & & \\
\hline
\end{tabular}

Values are presented as mean \pm standard deviation.

$\mathrm{BHI}$ : brain heart infusion, $\mathrm{NaF}$ : sodium fluoride, BS: bamboo salt.

${ }^{*} \mathrm{p}<0.05$, by Kruskal-Wallis test.

a,b,c,d The same letter indicates no significant difference by Mann-Whitney test. 
anti-microbial effect of $\mathrm{NaF}$ and $\mathrm{BS}$, and whether a mixture of NaF and BS could modify the cariogenic properties of $S$. mutans for prevention of dental caries was investigated.

BS has been known to have therapeutic effects on dental caries, inflammation, and viral infectious diseases ${ }^{3,5}$. The majority of table salts in Korea are purified salt (PS) and SDS. However, the quality of SDS is not adequately pure possibly due to seawater contamination, and PS is known to have a different component of biological electrolytes ${ }^{15)}$. These facts have led to increasing use of "healthpromoting" salts, such as BS, by the general population. Incipient artificial enamel lesions treated with BS exhibited increased surface hardness and mineral levels. The mixture of $\mathrm{NaF}$ and $\mathrm{BS}$ resulted in significantly increased remineralization effects on artificial enamel caries ${ }^{5}$.

Fluoride interferes with bacterial metabolism and inhibits bacterial growth ${ }^{16)}$. This study also found that fluoride reduced $S$. mutans growth and acid production. Although the results demonstrated the inhibitory effect of NaF treatment on $S$. mutans, it is indefinite whether the treatments physiologically affected the function of other bacterial-related factors. As such, further studies are required to investigate bacterial interactions among dental biofilm microorganisms when $\mathrm{NaF}$ and $\mathrm{BS}$ are administered. This may lead to a deeper understanding of the bacterial community involved in dental caries pathology ${ }^{17}$.

One important factor inducing dental caries is acidity. The $\mathrm{pH}$ differences in BS- and NaF-treated $S$. mutans cultures were compared with those grown in BHI. The $\mathrm{pH}$ of BS-treated samples was similar to that of $0.05 \%$ $\mathrm{NaF}$-treated bacterial cells; however, the mixture of $\mathrm{NaF}$ and $\mathrm{BS}$ led to a slight decrease in $\mathrm{pH}$ compared with samples treated with $\mathrm{BS}$ or $\mathrm{NaF}$ alone. It has been reported that the $\mathrm{pH}$ of $\mathrm{BS}$ can influence anti-inflammatory activity $^{3)}$. The BS and $\mathrm{NaF}$ mixture also resulted in a reduction of acid production. Thus, a combination of BS and $\mathrm{NaF}$ would result in increased anti-cariogenic activity.

In this study, it was found that various cariogenic conditions, such as acidogenicity and bacterial adhesion, were inhibited by treatment with $\mathrm{NaF}$ and BS. The NaF and BS group inhibited $S$. mutans growth and adhesion. Especially, the group with mixture of $\mathrm{BS}$ and $\mathrm{NaF}$ exhibited inhibitory effects that were more effective on the growth and adhesion of $S$. mutans than the $\mathrm{BS}, \mathrm{NaF}$, and control groups did. The mixture suppressed the expression of $S$. mutans biofilm-related $g t f \mathrm{~B}, g t f \mathrm{C}, g t f \mathrm{D}$, and $f t f$ genes (Fig. 1). Among them, the expression of gtfB demonstrated the greatest reduction in the $0.05 \% \mathrm{NaF}+3 \% \mathrm{BS}$ mixture. $g t f \mathrm{~B}$ is an important virulence gene associated with the pathogenesis of biofilm formation and dental caries $^{18)}$. More detailed gene expression profiling, however, is needed for a deeper understanding of the molecular mechanisms involved in the synthesis of biofilms in the presence of $\mathrm{NaF}$ and $\mathrm{BS}$.

The $0.02 \% \mathrm{NaF}+3 \% \mathrm{BS}$ mixture was found to effect the activity of $S$. mutans by four routes: reduced adhesion of $S$. mutans to glass beads after incubation; reduced growth of $S$. mutans; repressed acid production by $S$. mutans; and modulation of the expression of specific genes including $g t f \mathrm{~B}, g t f \mathrm{C}, g t f \mathrm{D}$, and $f t f$. These findings demonstrate that a combination of $\mathrm{NaF}$ and $\mathrm{BS}$ can inhibit the cariogenic activity of $S$. mutans, and that a mouth rinse consisting of this mixture may be useful in preventing dental caries.

\section{Notes}

\section{Conflict of interest}

No potential conflict of interest relevant to this article was reported.

\section{Ethical approval}

This project does not require IRB review because it is an experimental paper using commercially available microorganisms.

\section{ORCID}

Hye-Jin Lee, https://orcid.org/0000-0003-3923-0447

A-Reum Park, https://orcid.org/0000-0002-6009-8850

Han-Na Oh, https://orcid.org/0000-0003-0811-2405

\section{Acknowledgements}

This study was supported by Howon University in 2019. 


\section{References}

1. Kuramitsu HK: Virulence properties of oral bacteria: impact of molecular biology. Curr Issues Mol Biol 3: 35-36, 2001.

2. Kuramitsu HK: Virulence factors of mutans streptococci: role of molecular genetics. Crit Rev Oral Biol Med 4: 159-176, 1993. https://doi.org/10.1177/10454411930040020201

3. Shin HY, Lee EH, Kim CY, et al.: Anti-inflammatory activity of Korean folk medicine purple bamboo salt. Immunopharmacol Immunotoxicol 25: 377-384, 2003.

https://doi.org/10.1081/iph-120024505

4. Chung SY, Yi SY, Rheu HM, et al.: Pharmacological evaluation of bamboo salt. Biomol Ther 7: 178-184, 1999.

5. Choi $\mathrm{CH}$, Lee HJ, Oh HN, Hong SJ: Evaluation of the remineralization effect of bamboo salt and sodium fluoride solutions. J Korean Acad Oral Health 36: 7-12, 2012.

6. Petersen FC, Assev S, Scheie AA: Combined effects of NaF and SLS on acid- and polysaccharide-formation of biofilm and planktonic cells. Arch Oral Biol 51: 665-671, 2006. https://doi.org/10.1016/j.archoralbio.2006.02.003

7. Filoche SK, Soma K, Sissons CH: Antimicrobial effects of essential oils in combination with chlorhexidine digluconate. Oral Microbiol Immunol 20: 221-225, 2005. https://doi.org/10.1111/j.1399-302X.2005.00216.X

8. Takarada K, Kimizuka R, Takahashi N, Honma K, Okuda K, Kato T: A comparison of the antibacterial efficacies of essential oils against oral pathogens. Oral Microbiol Immunol 19: 61-64, 2004.

https://doi.org/10.1046/j.0902-0055.2003.00111.x

9. Oh HN, Choi $\mathrm{CH}$ : Effect of bamboo salt on the caries activity of Streptococcus mutans. J Korean Acad Oral Health 40: 238-243, 2016. https://doi.org/10.11149/jkaoh.2016.40.4.238
10. Park YN: The effect of erythritol on gtf and $\mathrm{ftf}$ expression from Streptococcus mutans. Unpublished doctoral dissertation, Chonnam National University, Gwangju, 2011.

11. Tarsi R, Muzzarelli RA, Guzmán CA, Pruzzo C: Inhibition of Streptococcus mutans adsorption to hydroxyapatite by low-molecular-weight chitosans. J Dent Res 76: 665-672, 1997. https://doi.org/10.1177/00220345970760020701

12. Baehni PC, Takeuchi Y: Anti-plaque agents in the prevention of biofilm-associated oral diseases. Oral Dis 9 Suppl 1: 23-29, 2003. https://doi.org/10.1034/j.1601-0825.9.s1.5.x

13. Ooshima $\mathrm{T}$, Minami $\mathrm{T}$, Aono $\mathrm{W}$, et al.: Oolong tea polyphenols inhibit experimental dental caries in SPF rats infected with mutans streptococci. Caries Res 27: 124-129, 1993. https://doi.org/10.1159/000261529

14. Scheie AA: Modes of action of currently known chemical anti-plaque agents other than chlorhexidine. J Dent Res 68: 1609-1616, 1989.

15. Kim YH, Ryu HI: Elements in a bamboo salt and comparision of its elemental contents with those in other salts. Yakhak Hoeji 47: 135-141, 2003.

16. Bradshaw DJ, Marsh PD, Hodgson RJ, Visser JM: Effects of glucose and fluoride on competition and metabolism within in vitro dental bacterial communities and biofilms. Caries Res 36: 81-86, 2002. https://doi.org/10.1159/000057864

17. Kuramitsu HK, He X, Lux R, Anderson MH, Shi W: Interspecies interactions within oral microbial communities. Microbiol Mol Biol Rev 71: 653-670, 2007. https://doi.org/10.1128/MMBR.00024-07

18. Yamashita Y, Bowen WH, Burne RA, Kuramitsu HK: Role of the Streptococcus mutans gtf genes in caries induction in the specific-pathogen-free rat model. Infect Immun 61: 3811-3817, 1993. 